\title{
The Effect of Pollution Reduction Program for Used Diesel Vehicles in Seoul Metropolitan Area: A Real Option Analysis ${ }^{\dagger}$
}

\author{
Hojeong Park* and Jong Ho Hong**
}

ABSTRACT : This paper attempts to evaluate an environmental regulation program which enforces installation of filtering equipment to reduce major air pollutants from used diesel vehicles. A real option model is presented to incorporate fuel cost uncertainty and irreversibility of emission-reducing investment. A finite-life option based on finite difference method is developed to consider the limited life expectancy of used vehicles. After taking into account social benefits from emission reduction and costs from decreasing fuel efficiency after the adoption of filtering technology, the result finds overall positive performance of the Pollution Reduction Program. However, the result suggests that the Program be designed to be more specific to vehicle types to improve program performance.

Keywords : pollution reducing investment, real option, social benefit-cost analysis

JEL 분류: Q52, Q58, H43

Received: May 26, 2014. Accepted: September 15, 2014.

${ }^{\dagger}$ This work is financially supported by the National Research Foundation of Korea Grant (NRF-2013S1A 3A2055150). The original data used in this paper is obtained through the assessment report of KDI (2007) on the Pollution Reduction Program, to which both authors made significant contributions.

* Professor, 1st author, Department of Food and Resource Economics, Korea University. Seoul, Korea (e-mail: hjeongpark@korea.ac.kr)

** Professor, Corresponding author, Graduate School of Environmental Studies and Asian Institute for Energy, Environment and Sustainability, Seoul National University, Seoul, Korea (e-mail: hongjongho@snu.ac.kr) 


\title{
수도권 운행차 대기오염 저감사업의 효과: 실물옵션분석
}

\author{
박호정* · 홍종호**
}

요 약 : 수도권 미세먼지 발생저감 대책의 일환으로, 노후화된 경유차에서 발생하는 주요 대기 오염물질 배출을 저감하기 위한 수도권 운행경유차 공해저감 사업이 시행되었다. 본 사업의 사 회적 경제성을 평가하기 위한 방법론을 제시하고, 주요 차량 배출저감장치의 유효성을 비교 분 석하였다. 방법론적으로는 노후화된 차량의 차령이 유한하기 때문에, 본 사업의 평가에 적합하 도록 만기유한 형태의 실물옵션 모형을 개발하였다. 분석 결과, 공해저감 사업의 사회적 경제성 은 전반적으로 확보되며, 버스와 트럭별로 저감장치를 구분하여 선택적으로 이루어질 때 그 효 과가 더욱 제고되는 것으로 나타났다.

주제어 : 공해저감 사업, 사회적 경제성, 실물옵션

접수일(2014년 May월 26일), 게재확정일(2014년 September월 15일)

* 고려대학교 식품자원경제학과 교수, 제1저자(e-mail: hjeongpark@korea.ac.kr)

*** 서울대학교 환경대학원 교수, 교신저자(e-mail: hongjongho@snu.ac.kr) 
The Effect of Pollution Reduction Program for Used Diesel Vehicles in Seoul Metropolitan Area: A Real Option Analysis

\section{Introduction}

The problem of air pollution in the Seoul metropolitan area is severe due to the high density of population and increasing economic activity. According to the Ministry of Environment of Korea, the concentration rates of $\mathrm{PM}$ and $\mathrm{NO}_{2}$ in Seoul are approximately 2.5 and 1.4 times higher, respectively, compared to other densely populated metropolitan cities such as New York, Paris, and Tokyo. In addition, the air pollution of PM and NOx in Seoul metropolitan area is worse than other local cities in Korea, thereby increasing the possibility of early deaths as well as the associated acute respiratory diseases.

In particular, as evidenced by recently increasing ultrafine dust problems, it is important to extend our efforts in order to curb the emission of flow pollutions such as PM and NOx. There are many urgent issues to be investigated to resolve the fine dust problem, since the generation and diffusion mechanisms of the fine dust are not yet completely identified, e.g., it is not clear how much of pollutions are transferred from China and generated in the domestic area. It is obvious, however, that some, if not all, of the pollution can be mitigated by the domestic policy measures to control the emission source. An example to control heavy air pollution in metropolis is found in Paris, which recently introduced a drastic measure to allow drivers to use their vehicles on alternate days.

Noting that driving diesel vehicles is one of the major sources of air pollution, the Korean government initiated in 2005 an environmental regulatory policy measure called Pollution Reduction Program (PRP, hereafter). Primary purpose of the PRP is to enhance ambient air quality by encouraging the adoption of pollution reduction equipment such as DPF (diesel particulate filter) or pDPF (partial DPF) to reduce pollutants. According to the Program, diesel vehicles can be equipped with (p)DPFs, which is financially subsidized to cover $70 \sim 95 \%$ of the installation costs by the government. Another option under the PRP is to convert diesel engines 
to LPG fuel compatible engine.

The PRP has been widely supported because it could achieve high removal efficiency in reducing PM, HC, NOx or CO. On the other hand, it has been frequently reported that the installation of DPF reduces fuel efficiency, thereby resulting in fuel cost increase (KDI, 2007). To some extent, the latter effect would obviously undermine the performance of PRP from the social perspective by attenuating the net benefit of pollution reduction.

Given that the PRP requires substantial government budget more than 200 million dollars annually to subsidize approximately 140,000 used diesel vehicles (KDI, 2007), it is critically important to evaluate social benefits and costs of the PRP. A series of reports on the preliminary feasibility study argued that (p)DPF generally satisfies economic feasibility criterion with benefit cost ratio larger than 1 (National Assembly Budget Office, 2005; Kang, 2003). Unlike ex ante benefit cost analysis of Kang (2003), this paper aims at providing an interim feasibility analysis so as to improve the effectiveness of the PRP. Partial list for similar studies on the effect of the PRP for diesel vehicles includes Voohres (2004), Pandey (2004) and Stevens et al. (2005), which analyzed the cases of Tokyo, Delhi and Mexico City, respectively. Hong and Park (2008) performed benefit cost analysis of the PRP to assess the interim performances of the PRP program.

This paper makes further contribution to the literature by examining vehiclespecific effects of the PRP and by developing an appropriate assessment model. In particular, two major issues are considered. First, there exists the possibility of irreversibility problem. Once (p)DPF is adopted for emission reduction, it is costly to disinstall it. As manifested by Dixit and Pindyck (1994), such irreversibility involves opportunity costs that must be explicitly considered from the initial stage of investment decision. Second, diesel fuel cost is subject to uncertainty influenced by the international crude oil price. The lower fuel efficiency as a result of the DPF adoption is known to cause additional fuel costs increase which is subject to 
The Effect of Pollution Reduction Program for Used Diesel Vehicles in Seoul Metropolitan Area: A Real Option Analysis

uncertain market price condition.

In this regard, we employ a real option model to simultaneously encompass aforementioned irreversibility and uncertainty issues in evaluating feasibility of the PRP. In particular, due to a limited life expectancy of used diesel vehicles, a real option structure must be based on a finite life option for (p)DPF installation. Unlike the perpetual American option which does not have any specific date for the option life, a finite life option does not entail closed form solutions. Hence, a numerical analysis is adopted in the paper to empirically examine the economic performance of the PRP.

The paper is organized as follows: Section 2 provides a brief policy overview on the PRP to control air pollution in the capital region. Section 3 presents a theoretical model for the real option analysis, which, in Section 4, is used in its empirical study to show the outcomes of the PRP. Conclusions and implications for air pollution policy are presented in Section 5 .

\section{Policy Overview}

As environmental amenity has been substantially degenerated since 1990s as a result of the unprecedentedly high level of air pollution in the capital region, the "Special Law to Improve Air Quality in Seoul Metropolitan Area" was enacted in 2005. The major measures include the control of noxious pollutants from diesel vehicles and introduction of low pollution vehicles such as LNG buses. Diesel vehicles failing to pass the required emission tests must choose one of several pollution reduction measures. They may install either one of PDF, pDPF or DOC to reduce particulates from vehicles. The other option they may choose is to convert engine to be LPG compatible instead of using diesel, or they may early retire the failing vehicles.

When either DPF or pDPF is installed, or LPG engine conversion is adopted, 
vehicle owners will get subsidy from the government that covers $95 \%$ of the total installation cost. The subsidy provided by the government is equally shared between the central and local governments: $47.5 \%$ for each, respectively. The subsidy rate for (p)PDF installation is much higher than the case when a vehicle owner chooses to take an early retirement option under the PRP, where the subsidy covers only $50 \%$ of the used car values.

According to the long-term plan of the PRP set by the Ministry of Environment, a total of 3.58 trillion won of government fund is scheduled during 2005 2014. It consists of 2.43 trillion won for PDF, 0.17 trillion won for DOC, 0.74 trillion won for LPG engine conversion, and 0.23 trillion won for early retirement. In 2004 when a pilot project was implemented before the introduction of the special law, 2,664 diesel vehicles operated by public institutes and non-profit organizations installed pollution reduction equipments. Approximately 42,000 intercity buses and freight trucks owned by private firms were targeted in 2005. In 2006, all vehicles failing the emission tests had to employ one of the mandatory pollution reduction measures. In addition, as a result of efforts to increase policy effects, voluntary mechanism was adopted in May 2006, by which even vehicle owners not failing the emission tests become eligible to receive government subsidy when they participate in the Program.

The Ministry of Environment evaluated pollution reduction performances of DPF and pDPF that were installed in 2005. The result shows that almost $80 \%$ of PM and $\mathrm{HC}$ are reduced by the installation of DPF. In contrast, the reduction rate of pDPF is relatively low with $50 \%$ of PM and $60 \%$ of HC. It should be noted that NOx is not considered in the study, since neither DPF nor pDPF controls NOx. We use a bottom-up approach to assess changes in fuel efficiency and pollution emissions for PM, CO and HC once DPF and pDPF are installed. Data for driving mileage and pollution emissions are compiled by using KDI database (2007). All results are summarized in Table 1. 
The Effect of Pollution Reduction Program for Used Diesel Vehicles in Seoul Metropolitan Area: A Real Option Analysis

〈Table 1〉 Specifications of fuel efficiency and pollutants per vehicle type

\begin{tabular}{|c|c|c|c|c|c|c|c|}
\hline & \multirow[t]{2}{*}{$\begin{array}{c}\text { Vehicle } \\
\text { Type }\end{array}$} & $\begin{array}{c}\text { Fuel } \\
\text { Efficiency } \\
\text { (A) }\end{array}$ & $\nabla(\mathrm{A})$ & $\begin{array}{l}\text { Driving } \\
\text { Mileage }\end{array}$ & $\begin{array}{c}\nabla \text { PM kg } \\
\text { per } \\
\text { vehicle }\end{array}$ & $\begin{array}{c}\nabla \mathrm{CO} \mathrm{kg} \\
\text { per } \\
\text { vehicle }\end{array}$ & $\begin{array}{c}\nabla \mathrm{HC} \mathrm{kg} \\
\text { per } \\
\text { vehicle }\end{array}$ \\
\hline & & (km/liter) & $(\%)$ & (km/day) & (kg/quarterly) & (kg/quarterly) & (kg/quarterly) \\
\hline \multirow{9}{*}{$\begin{array}{l}\mathrm{D} \\
\mathrm{P} \\
\mathrm{F}\end{array}$} & City bus & 2.35 & 0.02 & 254 & 6.33 & 71.07 & 28.25 \\
\hline & Intercity bus & 2.35 & 0.02 & 273 & 4.33 & 42.67 & 17.10 \\
\hline & Chartered bus & 2.35 & 0.02 & 163 & 0.86 & 19.12 & 6.70 \\
\hline & Express bus & 2.35 & 0.02 & 292 & 30.00 & 296.05 & 90.79 \\
\hline & Other bus & 2.35 & 0.02 & 128 & 1.92 & 12.67 & 3.87 \\
\hline & Midsize van & 7.00 & 0.02 & 56 & 0.57 & 13.44 & 3.44 \\
\hline & Midsize truck & 4.50 & 0.02 & 93 & 1.30 & 22.96 & 5.25 \\
\hline & Large size truck & 4.00 & 0.02 & 170 & 6.73 & 37.65 & 9.53 \\
\hline & Special truck & 3.50 & 0.02 & 55 & 5.57 & 17.31 & 4.05 \\
\hline \multirow{7}{*}{$\begin{array}{l}\mathrm{p} \\
\mathrm{D} \\
\mathrm{P} \\
\mathrm{F}\end{array}$} & Midsize van & 7.00 & 0.02 & 56 & 0.53 & 8.96 & 2.58 \\
\hline & City bus & 2.35 & 0.02 & 254 & 2.52 & 31.63 & 14.19 \\
\hline & Chartered bus & 2.35 & 0.02 & 163 & 1.28 & 12.75 & 5.02 \\
\hline & Other bus & 2.35 & 0.02 & 128 & 0.98 & 8.45 & 2.90 \\
\hline & Midsize truck & 4.50 & 0.02 & 93 & 1.18 & 15.31 & 3.94 \\
\hline & Large size truck & 4.00 & 0.02 & 254 & 4.79 & 25.10 & 7.15 \\
\hline & Special truck & 3.50 & 0.02 & 55 & 2.02 & 11.54 & 3.04 \\
\hline
\end{tabular}

\section{Model}

The value of investment opportunity is analyzed under the framework of a real option model. In the presence of uncertainty, net present value method may mislead to non-optimal decision by failing to consider managerial flexibility in decision making process and irreversibility nature of investment cost (see Dixit and Pindyck, 1994).

As diesel vehicles which are more than 10 years old are eligible for this Program, we assume 5 years of remaining life expectancy. In this regard, an American option model with a finite life is appropriate because the decision whether to install or not 
must be made within 5 years. Furthermore, since all the vehicles are used ones, it is assumed they will last 4 years after the installation of PRP options. This allows a finite project life, which must be solved by numerical analysis such as finite difference methods (Wilmott, 2000). Fuel price uncertainty is modeled by assuming the stochastic process

$$
d p(t)=\alpha p(t) d t+\sigma p(t) d z(t)
$$

where $d z(t)$ is the increment of standard Wiener process with $E(d x)=0$ and $\operatorname{Var}(d z)=d t$ and $p(0)=p$ It is assumed that the drift parameter $\alpha$ and the volatility parameter $\sigma$ are time invariant.

We consider four types of pollutants emitted from diesel vehicles: PM, NOx, CO and HC. Environmental cost of each ton of pollutant is denoted by $c_{i}$ for $i=1, \ldots, 4$ in the order of PM, NOx, CO and HC. Thus, total environmental benefit in the quarterly period is $\sum_{i=1}^{4} R_{i} c_{i}$, where $R_{i}$ denotes the amount of $i$ th emission reduction after DPF installation.

The quarterly fuel cost is represented by $p m \mu_{s}$ where $m$ is the total driving distance per quarterly period, and $\mu_{s}$ is the inverse of fuel efficiency before $(s=0)$ and after $(s=1)$ the installation of pollution reduction equipments, respectively. Therefore, the change of fuel cost after the program participation is $p m\left(\mu_{1}-\mu_{0}\right)$ Thus, in combination with the environmental cost, the present value of net benefit from is

$$
V(p)=E \int_{0}^{t}\left(\sum_{i=1}^{4} R_{i} c_{i}-p m\left(\mu_{1}-\mu_{0}\right)\right) e^{-r t} d t
$$

where $E$ is expectation operator and $r$ is social discount rate. The solution to (2) is given by 
The Effect of Pollution Reduction Program for Used Diesel Vehicles in Seoul Metropolitan Area: A Real Option Analysis

$$
V(p)=\frac{\sum_{i=1}^{4} R_{i} c_{i}}{r}\left(1-e^{-r T}\right)-\frac{p m\left(\mu_{1}-\mu_{0}\right)}{r-\alpha}\left(1-e^{-(r-\alpha) T}\right) .
$$

Before the program implementation, an option to invest is sustained until the stochastic fuel price flow reaches sufficient level of threshold, which will be determined in the following analysis. Let $\tau$ denote the remaining time to option expiry date. Using the Ito's lemma, it can be shown that the option value denoted by $F(p, \tau)$ satisfies the following partial differential equation

$$
r F(p, \tau)=F_{\tau}+\alpha p F^{\prime}(p, \tau)+\frac{1}{2} \sigma^{2} p^{2} F^{\prime \prime}(p, \tau) .
$$

In contrast to perpetual option, the expiry date for the option corresponding to (4) is finite due to limited durability of vehicles. Since this option must satisfy the terminal conditions at the option expiry date $T$, there is in general no closed form solution to (4). Therefore, we rely on a numerical analysis to obtain $c$.

Our objective is to find a threshold at which it is optimal to exercise PRP option. It is conceptually equivalent to find an optimal exercise time, $\tau^{*}=\inf \left\{t \mid p \leq p^{*}\right\}$ which satisfies the following boundary condition: $F\left(p^{*}\right)=V\left(p^{*}\right)-K$ and $\partial F\left(p^{*}\right) / \partial p=\partial V\left(p^{*}\right) / \partial p$, where $K$ is the installation cost. The first condition which is called a value-matching condition means the equivalence of the investment option values and the value of the investment less the investment cost. Hence, it simply indicates a condition at which net benefit of investment is zero. The latter condition, i.e., smooth-pasting condition, implies a sort of optimal condition, the marginal option value being equal to the marginal values of the investment.

When there is no specific expiry date, it is straightforward to derive the solution to equation and the optimal threshold for the installation. Without presenting the detailed part of derivation process, the optimal threshold $p^{* *}$ can be derived as follows: 


$$
p^{* *}=\frac{\beta}{\beta-1}\left(\frac{r-\alpha}{m\left(\mu_{1}-\mu_{0}\right)}\right)\left(\frac{\sum_{i=1}^{4} c_{i} R_{i}}{r}-K\right)
$$

where $\beta$ is a solution of characteristic equation derived from the option value (refer to Dixit and Pindyck, 1994, for more details). Unfortunately, the finite option does not provide any well-known closed form solution. One popular way of numerical analysis in the absence of closed analytical solution is the finite differentiation method, among which Crank-Nicolson method is known for its superior performance. We will use Crank-Nicolson method because of its unconditional stability in the process of numerical analysis by combining forward, backward and central differences at the same time (Brandimarte, 2001). The following grid equation is a Crank-Nicolson type of representation of equation (4) that can be solved numerically:

$$
\begin{aligned}
& \frac{F_{i j}-F_{i-1, j}}{\Delta t}+\frac{r j \Delta p}{2}\left(\frac{F_{i-1, j+1}-F_{i-1, j-1}}{2 \Delta p}\right)+\frac{r j \Delta p}{2}\left(\frac{F_{i, j+1}-F_{i, j-1}}{2 \Delta p}\right) \\
& +\frac{\sigma^{2} j^{2}(\triangle p)^{2}}{4}\left(\frac{F_{i-1, j+1,}-2 F_{i-1, j}+F_{i-1, j-1}}{(\triangle p)^{2}}\right) \\
& +\frac{\sigma^{2} j^{2}(\Delta p)^{2}}{4}\left(\frac{F_{i, j+1}-2 F_{i, j}+F_{i, j-1}}{(\triangle p)^{2}}\right)=\frac{r}{2}\left(F_{i-1, j}+F_{i j}\right)
\end{aligned}
$$

where $i$ and $j$ represent the grid points for $p$ and time, respectively. Let $N$ and $M$ denote the number of time and state space steps, respectively. The discrete step for $p$ is defined by $\Delta p=\left(p_{\max }-p_{\min }\right) / M$. Matlab program is used to perform this finite American option analysis and to identify the option exercise time in terms of the threshold level c. It is optimal to install the (p)DPF when $p \leq p^{*}$, otherwise it is necessary not to exercise the installation investment option until the more information arrives in order to make a better judgment. 
The Effect of Pollution Reduction Program for Used Diesel Vehicles in Seoul Metropolitan Area: A Real Option Analysis

\section{Empirical analysis}

This section analyzes the performance of filtering equipments to mitigate PM, $\mathrm{CO}$ and $\mathrm{HC}$ emissions, which have been largely regarded as control targets to improve air quality in Seoul Metropolitan area. As noted above, major assessment index for the PRP is the amount of pollution reduced by the program. Since the effectiveness of filtering technology is critically dependent on vehicle types, we distinguish vehicles as following: City Bus, Intercity Bus, Chartered Bus, Express Bus, Other Bus, Midsize Van, Midsize Truck, Large Truck and others for DPF; Midsize Van, City Bus, Chartered Bus, Other Bus, Midsize Truck, Large Truck and Special Truck for pDPF. According to KDI (2007), PM is reduced by $80 \%$ and $50 \%$, respectively, by DPF and pDPF. HC is reduced by $80 \%$ and $60 \%$, respectively, by DPF and pDPF.

Social environmental benefit is the monetary value of improved environmental quality through the reduced pollutants. According to Kang (2003), which relies on Markandya (1998) in estimating the social costs of various pollutants, the social costs per ton of PM10, NOx, HC and CO in Korea are 28,583 won, 8,755 won, 7,276 won and 1,495 won, respectively, after appropriately taking into account the exchange rate and inflation-adjusted PPP.

Costs term needs to include the installation cost of (p)DPF as well as the cost of fuel efficiency loss after the filtering technology. The decrease of fuel efficiency after exercise of PRP option incurs additional fuel cost. The installation of DPF is known to reduce fuel efficiency by $2 \%$ (Hong and Park, 2008). The fuel cost is calculated by a formula: fuel efficiency $($ liter $/ \mathrm{km}) \times$ diesel price $($ won $/$ liter $) \times$ average driving millage $(\mathrm{km})$. In the model, every analysis is based on the quarterly period. The social discount rate is $5.5 \%$, which is the official rate used by the Korea Development Institute in evaluating large scale public programs and projects.

Using the diesel price data provided by Petronet, the Korea National Oil 
Corporation which is ranged from 1999:01 to 2005:12., we estimate drift and volatility parameters of diesel price. By defining $y_{t}=\ln p_{t}-\ln p_{t-1}$, the drift parameter is derived from $\bar{y}+s^{2} / 2$, where $\bar{y}$ and $s$ is the average and standard deviation of $y_{t}$, respectively. The estimation results are $\alpha=0.005$ and $\sigma=0.041$.

The option value satisfies the terminal condition of $F(p, 0)=\max (V(p)-K, 0)$ that must be solved by means of Crank-Nicolson method. The number of time steps is set with $N=100$ while the number of state space steps is $M=100$. The sufficiently low floor and high ceiling prices are set with $p_{\text {min }}=100$ and $p_{\max }=10000$, respectively. The value of $V(p)$ is given by equation (3).

〈Table 2〉 Parameter values for analysis

\begin{tabular}{c|c|c}
\hline Parameters & Values & Description \\
\hline$\alpha$ & 0.005 & Drift parameter \\
\hline$\sigma$ & 0.041 & Volatility parameter \\
\hline$r$ & 0.055 & Discount rate (KDI) \\
\hline$T$ & 20 & Option life (4 quarters and 5 years) \\
\hline$R$ & Reported in Table 1 & Reduction of pollution \\
\hline$m$ & Reported in Table 1 & Driving mileage \\
\hline
\end{tabular}

Thresholds for infinite life option case as in equation (5) are illustrated in Figure 1. The DPF installation is particularly suitable for intercity bus and express bus compared to other types of vehicles. For the case of pDPF, special truck and large truck possess much advantage relative to other types of vehicles.

As for the finite life option, we rely on the numerical analysis to find $p^{*}$ which satisfies the value-matching and smooth-pasting conditions. Figure 2 shows a convergence to the option threshold which satisfies the boundary conditions as time steps evolve following the grid points in the grid equation (6). Stability of numerical results could be assured by the concurrent applications of forward, backward and central differences. 
The Effect of Pollution Reduction Program for Used Diesel Vehicles in Seoul Metropolitan Area: A Real Option Analysis

〈Figure 1〉 Thresholds for infinite life option for DPF and pDPF installations

(unit: 1000KRW)

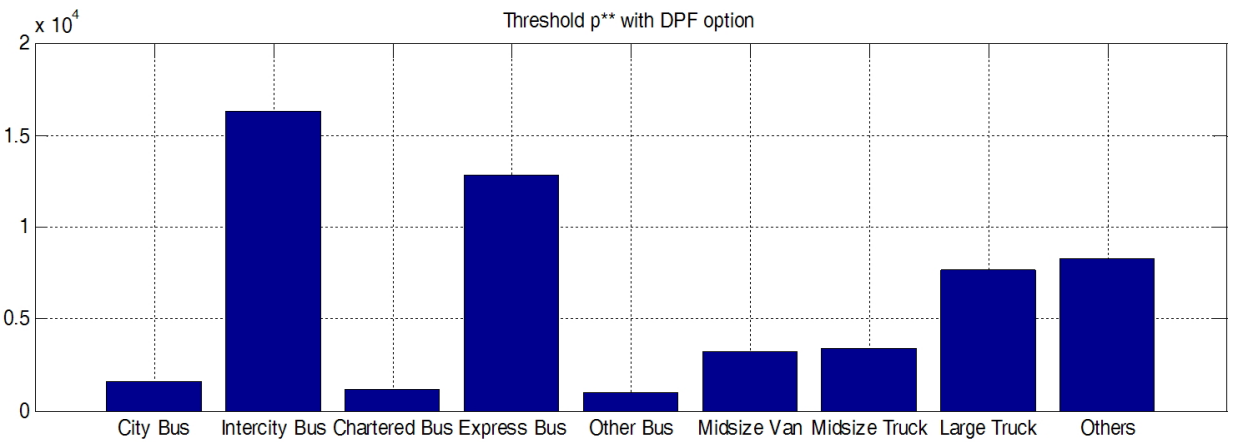

Threshold p** with pDPF option

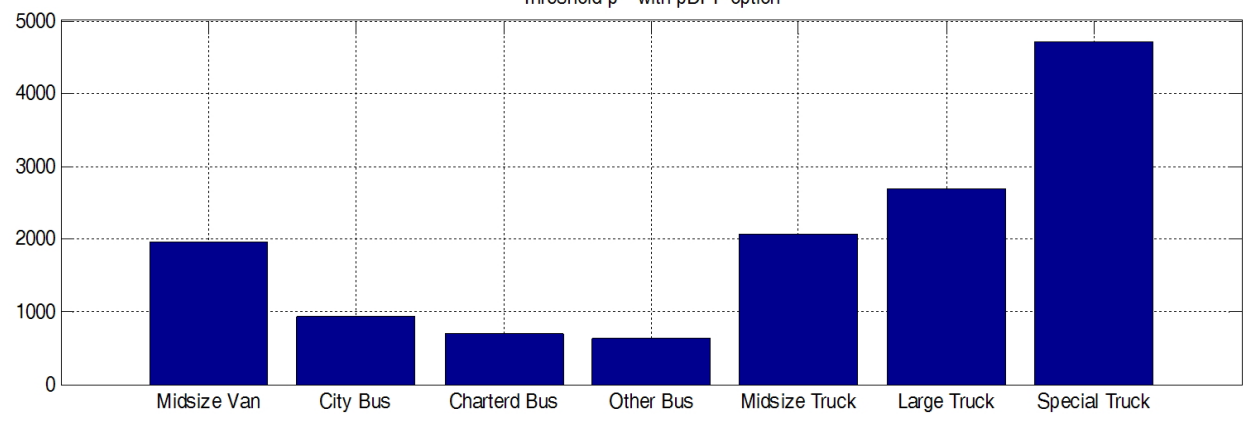

〈Figure 2〉 Numerical convergence to thresholds in Crank-Nicolson method

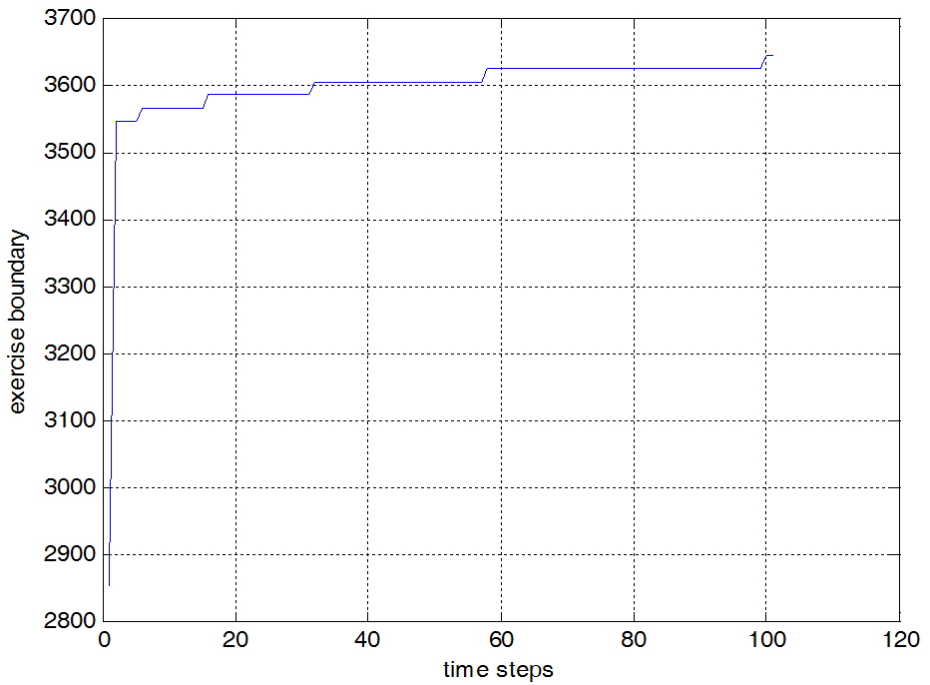


Once we identify the threshold $p^{*}$ for the terminal condition, the ratios of vehicle-specific thresholds to diesel price, $p^{*} / p$ are constructed as illustrated in Figure 3. If $p^{*} / p>1$, it implies that the fuel price is sufficiently low to ensure the effectiveness of PRP option. The result shows that the installation of $\mathrm{pDPF}$ is not optimal for most of buses while economic efficiency of $\mathrm{pDPF}$ for special truck is significantly high. Identical to the results of infinite life option, DPF outperforms at intercity and express bus. This implies that we need a distinct approach for DPF and pDPF with special focus on bus and truck, respectively, by DPF and pDPF.

In general, as Table 3 shows, economic efficiency for PDF is relatively larger than those of pDPF, particularly for large truck. Table 4 provides a sensitivity analysis with respect to volatility of diesel price. It confirms conventional real option result, where increasing uncertainty undermines economic feasibility of projects. In addition, Table 2 shows that inefficiency of pDPF for city bus is somewhat robust irrespective of volatility level. Our main finding implies that the PRP focus on specific advantages of (p)DPF depending on vehicle types to improve overall economic efficiency of the program, which was not suggested in the previous literature.

〈Table 3〉 Relative feasibility of DPF with respect to pDPF

\begin{tabular}{c|c|c|c}
\hline & DPF (A) & pDPF (B) & A/B \\
\hline Midsize Van & 3.0312 & 1.8404 & 1.6470 \\
\hline City Bus & 1.4518 & 0.8676 & 1.6734 \\
\hline Chartered Bus & 1.0494 & 0.6491 & 1.6167 \\
\hline Other Bus & 0.9624 & 0.5866 & 1.6406 \\
\hline Midsize Truck & 3.2122 & 1.9377 & 1.6577 \\
\hline Large Truck & 7.1612 & 2.5316 & 2.8287 \\
\hline
\end{tabular}


The Effect of Pollution Reduction Program for Used Diesel Vehicles in Seoul Metropolitan Area: A Real Option Analysis

〈Figure 3〉Economic feasibility of vehicles for DPF and pDPF installations

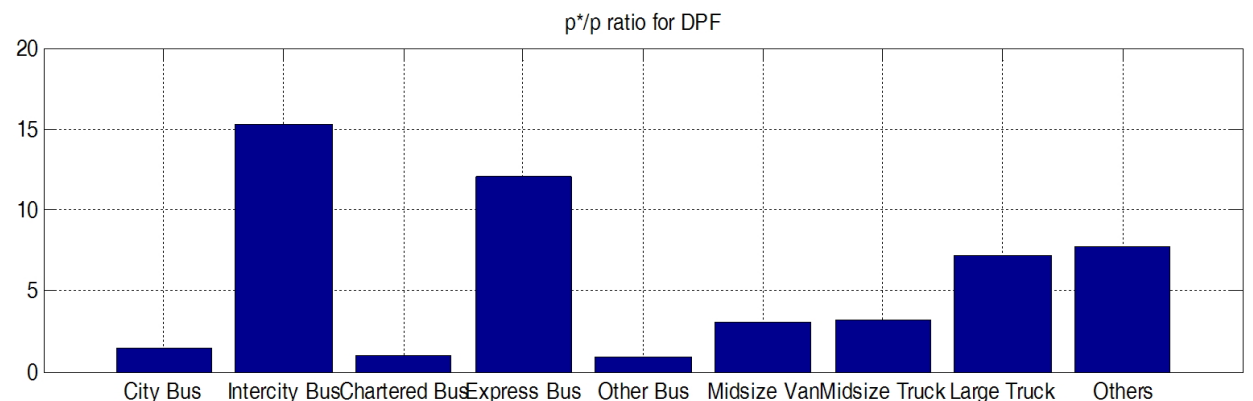

City Bus Intercity BusChartered BusExpress Bus Other Bus Midsize VanMidsize Truck Large Truck Others $\mathrm{p} \star / \mathrm{p}$ ratio for $\mathrm{pDPF}$

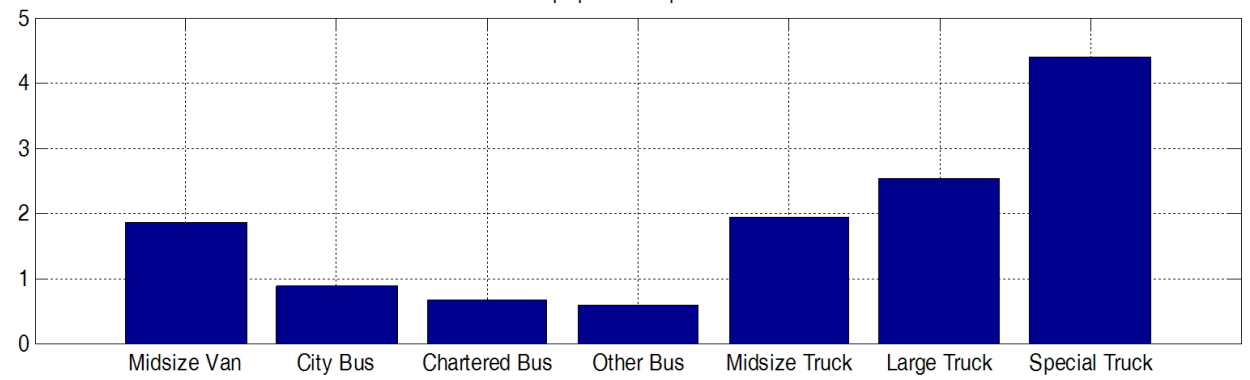

〈Table 4〉 Sensitivity analysis of economic feasibility of PDF and pDPF for buses

\begin{tabular}{c|c|c|c|c}
\hline & & $\sigma=0.021$ & $\sigma=0.041$ & $\sigma=0.081$ \\
\hline \multirow{3}{*}{ DPF } & City Bus & 1.5876 & 1.4521 & 1.1560 \\
\cline { 2 - 5 } & Chartered Bus & 1.1475 & 1.0494 & 0.8356 \\
\cline { 2 - 5 } & Other Bus & 1.0524 & 0.9624 & 0.7663 \\
\hline \multirow{2}{*}{$\mathrm{pDPF}$} & City Bus & 0.9487 & 0.8676 & 0.6908 \\
\hline
\end{tabular}

\section{Conclusion}

Fine dust, which is a precursor of flow air pollution, is a well-known source of many chronic diseases such as asthma, and lung-related disease. The social cost from fine dust is steadily increasing in Korea, which is evidenced by the recent ultrafine dust problem throughout Korea. Fine dust problem in Korea is partly 
attributed to trans-boundary pollution issue, which must be resolved by regional environmental cooperation between Korea and China. However, we need an alternative approach for fine dust which is generated domestically. That is, a domestic policy measure can be utilized to reduce PM from vehicles, which are one of the main sources of PM emission. A Notable example is the PRP, which has been implemented in the Seoul metropolitan area since the mid 2000s in order to provide an incentivized scheme to facilitate installation of filtering technology.

Our research serves as an analytic tool for the assessment of a public program to reduce emissions from used vehicles. After taking into account social benefits from emission reduction and costs from decreased fuel efficiency, we show that the PRP can contribute to alleviating severe air pollution problems in Seoul metropolitan area. Unlike the previous studies which do not analyze vehicle-specific effects of (p)DPF, this paper examines various types of vehicles by combining comprehensive data on daily driving distances and emissions of each pollutants.

The results imply that, despite overall positive performance of the Pollution Reduction Program, it can be designed to be more efficient by focusing on relative effectiveness of the (p)DPF on each type of vehicle, i.e., vehicle-specific policy: DPF for bus and pDPF for truck, for example. Moreover, in terms of methodological contribution, our paper shows a way to approach a particular type of option with a finite-life, which is particularly relevant for analyzing used vehicles. Such method can be readily applied to policy or economic feasibility assessment when there is a finite expiry date for option exercise.

We did not analyze the early retirement program for old diesel vehicles, which is another popular option for vehicle owners under the PRP. For the case of vehicle retirement, we need an exit-like option on the basis of put option structure. Future research can be extended to cover such approaches. 
The Effect of Pollution Reduction Program for Used Diesel Vehicles in Seoul Metropolitan Area: A Real Option Analysis

\section{[References]}

1. Brandimarte, P. (2002), Numerical Methods in Finance, Wiley Series.

2. Dixit, A. and Pindyck, R. (1994), Investment under Uncertainty, Princeton University Press.

3. Hong, J.H and H. Park (2008), "Benefit Cost Analysis of the Low Pollution Program for Diesel Vehicles in Seoul Metropolitan Area," Korean Journal of Public Finance, 1(2), 105-132 (in Korean).

4. Kang, K.G. (2003), Studies on Economic Feasibility of Clean Air Programs in Korea, Korea Environment Institute (in Korean).

5. KDI (2007), Emission Reduction Program for Diesel Vehicles, Ministry of Planning and Budget, Korea Development Institute (in Korean).

6. Markandya, A. (1998), Economics of Greenhouse Gas Limitations: The Indirect Costs and Benefits of Greenhouse Gas Limitations, UNEP.

7. National Assembly Budget Office (2005), Assessment of Clean Air Programs in Seoul Metropolis, NABO.

8. Pandey, R. (2004), "Economic policy instruments for controlling vehicle air pollution," Environment and Development Economics, 9, 47-59.

9. Stevens, G., A. Wilson, and Hammitt, J. K. (2005), "A benefit-cost analysis of retrofitting diesel vehicles with particulate filters in the Mexico City Metropolitan Area," Risk Analysis, 25(4), 883-899.

10. Voorhees, S. A. (2004), "Feasibility of cost-benefit analysis for particulate matter air pollution control in Japan," International Journal of Environmental Studies, 61(3), $315-325$

11. Wilmott, P. (2000), Quantitative Finance, Wiley, Chichester. 